\title{
Influence of writing style and categorical information on identification of tactile numerals and letters
}

\author{
MORTON A. HELLER, KIMBERLY D. NESBITT, and DANETTE K. SCROFANO \\ Winston-Salem State University, Winston-Salem, North Carolina
}

\begin{abstract}
Recognition of print capital letters, script letters, and numerals was studied in three experiments. In Experiment 1, letters printed on the skin with component lines in an irregular sequence were much harder to name than normally printed stimuli. In Experiment 2, categorical information was an important aid to letter or number identification. This obtained when subjects were required to draw the tactile stimuli. The results suggested that observers may not always construct a veridical "image" when stimuli are drawn on the skin in the absence of categorical information. Performance was much lower for script than for print letters or numerals. In Experiment 3, passive script recognition was superior to active script recognition. This suggested that passivity per se cannot always explain difficulty in tactile symbol recognition.
\end{abstract}

Our purpose in this study was to examine the impact of stimulus characteristics on passive touch. Touch is passive when the observer is immobile and stimulus objects are pressed on the skin (Gibson, 1962; Heller \& Myers, 1983) or drawn on the skin (Heller, 1980a, 1980b, 1986, 1987), or when the observer's finger or hand-held rod is guided over an outline (Heller \& Boyd, 1984). Passive touch has often been thought inferior to active touch (Gibson, 1962, 1966; see Heller, 1980a, 1980b, 1986). Numerals and letters are readily identified when individually drawn on the skin (Heller, 1986), but performance is reduced when sequences are drawn at a rapid rate (Heller, 1980b, 1986, 1987) or when categorical information is denied (Heller, 1986). Furthermore, shifts in orientation can sometimes degrade tactile pattern recognition in the sighted when orientation is variable (Heller, 1986) and in blind people (Heller, 1989).

Subjects in Experiment 1 identified patterns that were either normally drawn on the skin or drawn with unfamiliar sequences of component line segments. In Experiment 2, subjects identified print and script letters or digits, and the influence of categorical information was assessed. In Experiment 3, subjects identified engraved script either actively or passively, via exploration with a stylus.

\section{EXPERIMENT 1}

Identification of print capital letters written in a "normal" fashion was compared with identification of letters

Preparation of this report and the research were supported by NIH MBRS Grant 2 SO6 RR-08040. Faith Heller and Bill Schiff provided helpful comments on an earlier version of this manuscript. I wish to thank Bill Schiff for his suggestion that it might be difficult to "read" patterns with component lines drawn in atypical sequences. Send reprint requests to Morton A. Heller, Psychology, Winston-Salem State University, Winston-Salem, NC 27110. printed with component line segments in an unfamiliar, irregular sequence.

\section{Method}

Subjects. There were 28 sighted subjects, half of whom were males. Stimuli. The stimuli were print capital letters, A-Z. The letters were printed on the palm with a plastic stylus that had a smooth $.15-\mathrm{cm}$ rounded tip (see Heller, 1980a, 1980b, 1986, 1987). Vision was restricted by a Masonite baffle with a cloth-covered opening at its base. "Normal" letters were printed following the guidelines of the Helen Keller Center for the Deaf-Blind. The irregular letters were printed in an atypical manner. For example, the semicircle of the " $D$ " was drawn from the bottom up, before the vertical member was produced. Otherwise, the irregular patterns were identical to normal letters; only the sequence and direction of drawing component lines was changed. The letters were approximately $6 \mathrm{~cm}$ high, printed in the center of the preferred palm (as measured by writing preference).

Procedure. The subjects were told they would be required to identify print capital letters drawn on the skin of the preferred palm. Observers in the irregular condition were informed that the letters might not be printed in the usual manner, but would be taken from the entire alphabet. The 26 letters were drawn twice in a random arrangement for a total of $\mathbf{5 2}$ letters per subject. Feedback was not given as subjects vocally named each stimulus (see Heller, 1986, 1987, for further details).

\section{Results and Discussion}

Identification of normally printed letters was significantly better than identification of irregular letters $[t(26)=$ $5.6, p<.01]$. The mean number correct for normal print was $45.6(S D=3.2)$ and only $28.5(S D=10.9)$ for the irregularly printed capital letters. This suggests that letter identification depends on the recognition of a coherent spatiotemporal pattern of stimulation on the skin surface. A possible explanation of the results is that letter recognition was easier when the pattern of skin stimulation was similar to stored representations of the sorts of movement patterns involved in letter production. The sequence and direction of strokes may be critical. However, the relative importance of these factors is not known. In Experiment 2 , the influence of categorical information upon pattern recognition was examined. 


\section{EXPERIMENT 2 Categorical Information}

The subjects in Experiment 2 attempted to identify digits or letters printed or drawn in script on the skin of their palms. They were asked to draw the stimuli, so that the influence of categorical information on representation could be assessed.

\section{Method}

Subjects. The subjects were 28 undergraduates. None of the subjects had participated in Experiment 1. Half of the subjects were male and half were female.

Stimuli. The stimuli were individual digits (0-9) or capital letters (A-J), either printed or in script. Letters or digits were approximately $6 \mathrm{~cm}$ high, printed on the nonpreferred palm with the same stylus that was used in Experiment 1. ${ }^{1}$ Script letters followed the style of the script board used in Experiment 3. The response measure consisted of the use of the preferred hand (the right for all but 1 subject) to draw the patterns on rolled paper. The subjects were exposed to a random arrangement of the stimuli. Each letter or number appeared twice, for a total of 60 stimuli per subject.

Design and Procedure. The experimental design was a mixed-factor analysis of variance, with the variables being type of stimulus (number vs. print letter vs. script letter) and categorical information (subjects were told or were not told the stimulus category), with repeated measures on the type of stimulus. Some subjects were told the nature of the categorical status of each stimulus before its presentation, whereas others were simply told that patterns would be drawn on the skin. Observers were asked to draw each pattern immediately after its presentation. They were unable to see their hands behind the Masonite screen, but were permitted visual guidance as they drew the stimuli on paper. Responses were scored as correct if they were recognizable. In a couple of cases, the drawings were ambiguous, and the subjects were asked to name these drawings at the conclusion of the experiment. The subjects were not allowed to see their prior drawings as they depicted new stimuli.

\section{Results and Discussion}

Categorical information aided pattern identification (see Table 1). Performance was much lower for script than for print capital letters or numerals. A mixed-factor analysis of variance showed that the effect of stimulus type was highly significant $[F(2,52)=56.8, p<.001]$ and that the effect of prior information was significant $[F(1,26)=$ $11.1, p<.01]$; but the interaction was nonsignificant $(F<1)$. Letter and digit performance in the prior information condition was consistent with earlier results for the response measure of vocal naming (Heller, 1981).

Table 1

Effect of Categorical Information on Recognition of Print Letters, Script Letters, and Numbers Drawn on the Palm

\begin{tabular}{|c|c|c|c|c|c|c|}
\hline & \multicolumn{6}{|c|}{ Number Correct } \\
\hline & \multicolumn{2}{|c|}{ Print Letters } & \multicolumn{2}{|c|}{ Script } & \multicolumn{2}{|c|}{ Digits } \\
\hline & $M$ & $S D$ & $M$ & $S D$ & $M$ & $S D$ \\
\hline $\begin{array}{l}\text { No prior information } \\
\text { Prior categorical }\end{array}$ & 13.5 & 3.2 & 8.3 & 5.9 & 13.4 & 3.7 \\
\hline information & 16.8 & 2.4 & 12.1 & 3.0 & 18.1 & 1.5 \\
\hline
\end{tabular}

Note-The maximum score possible for each type of stimulus was 20 .

\section{EXPERIMENT 3 Active and Passive Tactual Script Recognition}

Active touch is often assumed to be superior (Gibson, $1962,1966)$ to passive touch, in which the observer makes no voluntary movements. In passive touch, information is imposed on a stationary observer (see Heller, 1980a, $1980 \mathrm{~b}, 1986$ ). Researchers have recently begun to question the universality of the advantage of active touch (e.g., Lederman, 1981). It is possible that active touch may be deficient and may lead to poor form perception, when the difficulties of movement control outweigh any possible aid derived from self-control over stimulation. Researchers have reported superior performance for passive touch under conditions in which little cutaneous information is available or shapes have to be explored with a stylus (Heller \& Boyd, 1984).

In Experiment 3, subjects used a stylus to explore engraved script letters, either actively or passively. The active subjects traced letters themselves; the passive subjects were aided by the experimenter, who guided their exploration. Because it was assumed that active exploration provides more "objective" information about the environment (Gibson, 1962, 1966), active tracing was expected to lead to superior script letter identification.

\section{Method}

Subjects. There were 20 subjects ( 10 active and 10 passive); half were males and half were females.

Stimuli and Apparatus. The 1.8-cm-high letters (A-O) were engravings on a script-writing board distributed by the American Foundation for the Blind. The board is used to instruct congenitally blind persons in writing script by having them trace the letters with a stylus. The letters were presented twice each in a random arrangement, for 30 trials per subject. Script letter recognition was compared with recognition of embossed printed letters via three independent groups of 10 subjects $(N=30)$. They attempted tactile recognition of the same 1.8-cm-high script letters embossed on paper (a product of the American Foundation of the Blind), printed letters on transparent Mylar film (with the Sewell Raised Line Drawing Kit), or touched printed capital letters (Helvetica, Fine) embossed on paper with a Freund writing screen and a braille stylus. Printed letters on paper (mean number correct $=27.5$ out of 30 trials) were more readily recognized than printed letters on Mylar $(M=19.5)$, and performance was somewhat lower for script on paper $(M=17.6)$. An analysis of variance showed that the effect of font style on accuracy was significant $[F(2,27)=15.4, p<.01]$. A Newman-Keuls test on mean number correct indicated that the mean for printed letters on paper was significantly higher than the other two means $(p<.01)$, but script on paper was not significantly different from printed letters on Mylar in ease of identification $(p>.05)$. Subjects were also more than twice as fast in their responses to printed letters on paper (mean latency $=12.3 \mathrm{sec}$ per character) $[F(2,27)=12.9$, $p<.01]$. Performance with embossed print on Mylar was much lower than that reported by Barr (1970), probably because her subjects benefited from practice with the stimuli.

Design and Procedure. All participants were able to view a drawing of the script letters during tactual examination. In the active group, the subjects were instructed to trace the letters with a stylus (a plastic braille eraser) "as if writing with a pen." They were always started at the top of each letter or where one might start to write the letter under normal circumstances. For passive tracing, each subject grasped the stylus while the experimenter repeatedly traced each of the grooved letters "as if 
writing" it. A maximum exposure time of $1 \mathrm{~min}$ was allowed in both conditions, and individuals were timed with a stopwatch.

The subjects were exposed to the 15 upright, script capital letters twice, in a random arrangement. Feedback was not given as observers attempted to name the letters. Vision was blocked by a Masonite screen, as in the first two experiments.

\section{Results and Discussion}

Recognition was very poor under conditions of active tracing (mean number correct $=13.2$ ). Passive tracing of script produced much higher accuracy $(M=23.9)$ $[t(18)=5.7, p<.01]$. Passive performance was high, at about $80 \%$ correct. Furthermore, passive recognition latencies were also significantly shorter $(M=15.8 \mathrm{sec}$ per character) than active tracing $(M=35.8 \mathrm{sec})[t(18)=6$, $p<.01$ ]. Active subjects had a great deal of trouble "finding their way" through the letters they traced. They sometimes appeared to get "lost" or "stuck" and repeatedly traced the same groove. Part of the difficulty of actively tracing script may derive from the complexity of the patterns, since performance was also low with script on paper. At least some of the problem, however, is due to a lack of cutaneous input during tracing with a stylus, since the present mean of $44 \%$ correct is lower than the score for active tracing with one's fingertip ( $59 \%$ correct).

\section{GENERAL DISCUSSION}

Taken together, the results of Experiments 1 and 2 suggest that subjects do not necessarily construct an accurate "image" when patterns are drawn on the skin. Symbol recognition clearly depends on the presentation of a coherent pattern of stimulation. Thus, when patterns were drawn with components in an unfamiliar sequence and stroke direction, subjects had great difficulty in the attempt to recognize letters. It is possible that the stimulus information for tactually drawn letters is higher order, involving familiar stroke-motion information. Pattern recognition is clearly dependent on the sequence and/or direction of strokes. These results are consistent with the suggestions of Parsons and his colleagues (e.g., Shimojo, Sasaki, Parsons, \& Torii, 1989) that link recognition to representation of movement patterns (Berman, 1939; Hulme, 1981). Therefore, one may be likely to recognize a pattern that one has already learned to generate. The results of Experiment 2 are also consistent with this interpretation, since categorical information aided pattern recognition. Drawing on the skin can be thought of as a process of communication, with the "listener" aided by knowledge of production rules (see Heller, 1986).

Experiment 3 yielded lower recognition for actively as opposed to passively experienced script. These results are consistent with other findings indicating that movement control can present problems for the perceiver with minimal cutaneous information. Optimal haptic performance entails coordinated input from the skin, muscles, and joints. The use of a probe can sometimes lower performance by diminishing cutaneous feedback and decoupling proprioceptive and cutaneous input (Heller, 1986; Heller \& Boyd, 1984). Active touch is probably most helpful in the early stages of learning, and it is not invariably beneficial (see Heller, Rogers, \& Perry, 1990). Moreover, active subjects may have examined the script letter shapes by using atypical movement sequences, since they lost their way while tracing patterns. This, of course, could have lowered recognition scores.

We should point out that the tasks studied in the present experiments occur in the natural environment. Touching with a probe is certainly an ecologically valid, useful skill. Blind people use long canes to explore their environment, and they can even identify surface qualities via auditory cues derived from tapping (Schenkman \& Jansson, 1986). Moreover, dentists, surgeons, and dental hygienists continually use probes, both to manipulate tissues and to gain textural and form information about underlying, invisible structures. Furthermore, the read- ing of patterns drawn on the skin (print on palm) is a preferred communication device of the deaf-blind (Heller, 1986), and it alters with practice (see O'Boyle \& Murray, 1988).

The present results have considerable bearing on the education of the visually impaired. Blind people should not be given script boards and left on their own. Script instruction with a template and a stylus will undoubtedly benefit from external guidance. Furthermore, other research suggests the value of coordinated cutaneous and proprioceptive input derived from the use of a raised-line drawing kit (Heller, 1991).

\section{REFERENCES}

BARR, R. L. (1970). Embossing Arabic letters and numbers on new raised-line polyethylene paper: An aid for the blind. Science, 169, 94-95.

Berman, A. (1939). The influence of the kinesthetic factor in the perception of symbols in partial reading disability. Journal of Educational Psychology, 30, 187-197.

Gibson, J. J. (1962). Observations on active touch. Psychological Review, 69, 477-490.

GiBson, J. J. (1966). The senses considered as perceptual systems. Boston: Houghton Mifflin.

Heller, M. A. (1980a). Reproduction of tactually perceived forms. Perceptual \& Motor Skills, 50, 943-946.

Heller, M. A. (1980b). Tactile retention: Reading with the skin. Perception \& Psychophysics, 27, 125-130.

Heller, M. A. (1981). Orientation and tactile symbol recognition. Perceptual \& Motor Skills, 53, 394.

Heller, M. A. (1986). Central and peripheral influences on tactual reading. Perception \& Psychophysics, 39, 197-204.

HeLler, M. A. (1987). Improving the passive tactile digit span. Bulletin of the Psychonomic Society, 25, 257-258.

Heller, M. A. (1989). Tactile memory in sighted and blind observers: The influence of orientation and rate of presentation. Perception, 18, 121-133.

HeLlER, M. A. (1991). Haptic perception in blind people. In M. A. Heller \& W. Schiff (Eds.), The psychology of touch (pp. 239-261). Hillsdale, NJ: Erlbaum.

Heller, M. A., \& Boyd, M. E. (1984). Touching with a wand. Perceptual \& Motor Skills, 58, 390.

Heller, M. A., \& MYers, D. S. (1983). Active and passive tactual recognition of form. Journal of General Psychology, 108, 225-229.

Heller, M. A., Rogers, G. J., \& Perry, C. L. (1990). Tactile pattern recognition with the Optacon: Superior performance with active touch and the left hand. Neuropsychologia, 28, 1003-1006.

Hulme, C. (1981). The effects of manual tracing on memory in normal and retarded readers: Some implications for multi-sensory teaching. Psychological Research, 43, 179-191.

LEDERMAN, S. J. (1981). The perception of surface roughness by active and passive touch. Bulletin of the Psychonomic Society, 18, 253-255.

O'Boyle, M. W., \& MURRAY, J. (1988). Hemispheric asymmetry in the identification of four-letter names traced in the right and left palms. Brain \& Language, 34, 294-301.

Schenkman, B. N., \& JANSson, G. (1986). The detection and localization of objects by the blind with the aid of long-cane tapping sounds. Human Factors, 28, 607-618.

Shimojo, S., SAsAkI, M., PArsons, L. M., \& TorI, S. (1989). Mirror reversal by blind subjects in cutaneous perception and motor production of letters and numbers. Perception \& Psychophysics, 45, 145-152.

\section{NOTE}

1. Two independent groups of 14 subjects attempted identification of the entire alphabet of script letters drawn either 1.8 or $6 \mathrm{~cm}$ high on the preferred palm. Letter recognition was better for the large script letters (mean number correct $=32.7$ ) than it was for the small script letters $(M=21.9)[t(26)=3, p<.01]$.

(Manuscript received March 11, 1991.) 